\title{
Evaluating the integration of supply chain information systems: A case study
}

\author{
Marinos Themistocleous ${ }^{\mathrm{a}}$, Zahir Irani ${ }^{\mathrm{a}, *}$, Peter E.D. Love ${ }^{\mathrm{b}}$ \\ a Information Systems Evaluation and Integration Network Group (ISEing), Department of Information Systems and Computing, \\ Brunel University, Uxbridge UB8 3PH, UK \\ ${ }^{\mathrm{b}}$ We-B Centre, School of Management Information Systems, Edith Cowan University, Churchlands, Perth, WA 6018, Australia
}

Available online 6 November 2003

\begin{abstract}
Supply chain management (SCM) is the integrated management of business links, information flows and people. It is with this frame of reference that information systems integration from both intra- and inter-organisational levels becomes significant. Enterprise application integration (EAI) has emerged as software technologies to address the issue of integrating the portfolio of SCM components both within organisations and through cross-enterprises. EAI is based on a diversity of integration technologies (e.g. message brokers, ebXML) that differ in the type and level of integration they offer. However, none of these technologies claim to be a panacea to overcoming all integration problems but rather, need to be pieced together to support the linking of diverse applications that often exist within supply chains. In exploring the evaluation of supply chain integration, the authors propose a framework for evaluating the portfolio of integration technologies that are used to unify inter-organisational and intra-organisational information systems. The authors define and classify the permutations of information systems available according to their characteristics and integration requirements. These, classifications of system types are then adopted as part of the evaluation framework and empirically tested within a case study.
\end{abstract}

(c) 2003 Elsevier B.V. All rights reserved.

Keywords: Supply chain; Enterprise application integration; Evaluation

\section{Introduction}

Many definitions exist in the normative literature for supply chain management. A definition reported by Lambert and Cooper [14] supports better the issues discussed in this paper. According to this definition

\footnotetext{
${ }^{*}$ Corresponding author. Tel.: +44-1895-816211; fax: +441895-816242.

E-mail address: zahir.irani@brunel.ac.uk (Z. Irani).
}

Supply chain management is the integration of key business processes from end user through original suppliers that provides products, services and information that add value for customers and other stakeholders.

$$
\text { Lambert and Cooper [14, p. 66] }
$$

A supply chain can be described as a network of relationships/connections between partners such as suppliers and customers. Many authors including Gunnarsson and Jonsson [9] have seen increased collaboration among the partners of a supply 
chain as a significant element in improving the management of the chain. Kalakota and Robinson [13] suggest that significant improvements in supply chain management can be achieved through the integration of business processes and information flows of the trading partners. Some of the benefits that are associated with the integration of supply chain systems include (a) gaining competitive advantage; (b) reducing operational costs and (c) achieving better collaboration and coordination among supply chain partners.

The integration of IS applications is an obstacle to many businesses, as supply chain partners consist of independent systems, that in many cases can not communicate one another. These autonomous and in many cases heterogeneous systems are historically not designed to collaborate with other applications, as supply chain partners have tended to develop their own systems independently and without any coordination. However, this strategy may result in a lack of enterprise architecture, common definitions, structures, protocols and business concepts [6]. This is further complicated by information systems being based on a plethora of different standards, computing languages, platforms and operating systems, which cause various integration problems such as incompatibility. There is also the complexity of existing information systems, which in many cases have fixed and rigid structures for messages, interfaces and databases. Moreover, there is a lack of documentation, especially as legacy systems have often emerged over the time without any focus strategy. Many legacy systems have existed in organisations for more than 25 years and their technical documentation was either not created or lost during the years. As a result, the integration of applications along a supply chain is a difficult and complex task.

Intra and inter-organisational integration is increasingly being achieved through enterprise application integration (EAI), which incorporates functionality from disparate applications and leads to cheaper, more functional and manageable IT infrastructures $[13,16,26]$. Application integration is based on a diversity of technologies such as message brokers, adapters and ebXML to incorporate systems. These technologies achieve inte- gration at different levels i.e. data, message, object, interface and/or process level. Nevertheless, there is no single integration technology that efficiently supports all integration levels [6,21]. Clearly, some integration technologies are more effective at one level of integration where others are at another. Therefore, a permutation of EAI technologies may be needed to overcome integration problems. However, there remains much confusion regarding the permutations of integration technologies that can be used to piece together information systems. The reason for this is that there are integration technologies that overlap in functionality but differ in the quality (e.g. portability, flexibility, scalability) and efficiency of their solutions. Moreover, the majority of applications that are pieced together differs in integration requirements, which means that the permutation of integration technologies is not only based on their functionality, but also on integration requirements and constrains.

This paper investigates the integration of supply chain management systems through EAI technologies. In doing so, Section 2 reviews the literature on supply chain management. Section 3 introduces EAI with Section 4 introduces the evaluation framework for assessing integration technologies. In Section 5 the proposed framework is tested through the use of empirical data.

\section{Supply chain management}

The need for improvements in supply chain management is not a new one but has existed for some time. During the last 20 years, organisations have achieved savings for supply chains through business process reengineering (BPR) and justin-time techniques. According to Gjerdrum et al. [8] such approaches focus at a single-enterprise level and therefore, while lacking of focus on the multi-enterprise supply chain optimization.

Many authors have discussed the issue of multienterprise collaboration to improve supply chain management. According to D'Amours et al. [4] a collaborative approach is more profitable than other alternatives. However, D'Amours et al. [4] mention that the impact of information sharing in networked organisations needs to be fully under- 
stood. The reasons for this are that many parameters such as strategy, control and human and organisational are affected by the sharing of information and business processes. Some of these factors may lead to conflicts among the staff or/ and the departments of a single organisation or between the departments of coupling partners [25]. Clearly, this is a research issue that should be further analysed and understood without restricting the adoption of integrated supply chain systems.

D'Amours et al. [4] advise that inter-organisational systems should be implemented to facilitate the electronic exchange of information flows. In support of this, Thonemann [30] suggests that information sharing is a significant area which is related with improvements in supply chain management. Typical information sharing practices include production schedules, demand forecasts and sharing of point-of-sale data. Integration of such information flows may result in handling high degrees of complexity.

The need for integrating supply chains has been explored by Bartezzaghi [1] and Spekman et al. [23], who suggest a more integrated and collaborative business model with a delegation of core processes. Such an approach could allow organisations to combine local and global information to obtain multi-focused, flexible processes. In addition, Spekman et al. [23], Gattorna [7] and Christopher [3] suggest that the integration of supply chains at a multi-enterprise level results in a competitive advantages and increases the overall performance of the supply chain.

Gattorna [7] states that information technology (IT) and their associated systems have transformed the way companies use their supply chain, consequently resulting in competitive differentiation. Similarly, Christopher [3] suggests that future competition will not be company against company but rather, supply chain against supply chain. This clearly presents interesting challenges when it comes to the integration of intra- and inter-organisational supply chain systems. As companies strengthen their relationships and collaborate at an inter-organisational level, the chain itself gains more links and therefore, increases management and coordination efforts.
An enterprise is no longer viewed as a single corporation; it is a loose collection of trading partners that can contract with manufacturers, logistics companies, and distribution organisations $[12,13]$. Therefore, a comprehensive integration of business processes and both intra- and interorganisational applications is required to support long-term coordination, survival and growth. Such integration increases the automation of business processes and significantly reduces manual tasks, redundancy of data and functionality. Also, an integrated inter-organisational IT infrastructure significantly reduces costs (e.g. maintenance, management, operational) and supports the achievement of competitive advantages through improving real-time response.

\section{Integrating the supply chains through enterprise application integration}

For many years, organisations have focused on electronic data interchange (EDI) technology to improve the automation of inter-organisational business processes and supply chains. Although organisations have gained significant benefits from the use of EDI, they turned to the use of the Internet due to EDI limitations (e.g. high cost, non-flexible technology) [24]. However, not all information systems can be integrated over the Internet (e.g. legacy systems) [15].

During the 1990s, enterprise resource planning (ERP) technology was introduced as an integrated approach to systems integration. ERP systems support generic processes that attempt to integrate the supply chains. At intra-organisational level this can be achieved more easily in cases where enterprises replace most of there IS with ERP modules. In such a scenario, ERP systems provide an integrated environment that supports supply chain management. As a result, ERP systems can improve customers' and suppliers' satisfaction and increase overall productivity. However, ERP systems have their own limitations as these systems need to be customised to fully support business processes and supply chains. Customisation is a difficult task that causes significant integration problems as ERP systems are complex, 
non-flexible and often not designed to collaborate with other autonomous applications. According to a survey published by Themistocleous et al. [28] companies experience significant difficulties when they customise $(72 \%)$ or integrate $(82 \%)$ their ERP systems with existing IS solutions. In addition, ERP systems co-exist along side other IS and thus, the integration of intra- and inter-organisational supply chains remains a significant problem for the majority of companies.

As the demand for integrating both intra- and inter-organisational systems and supply chains emerges, there is a need to use a technology that addresses integration problems and achieves business processes integration. This can be achieved through EAI that efficiently integrates functionality from disparate systems of a supply chain. As illustrated in Fig. 1, supply chain partners like producers, wholesalers, retailers and customers can use EAI technology at both intra-organisational and inter-organisational level.

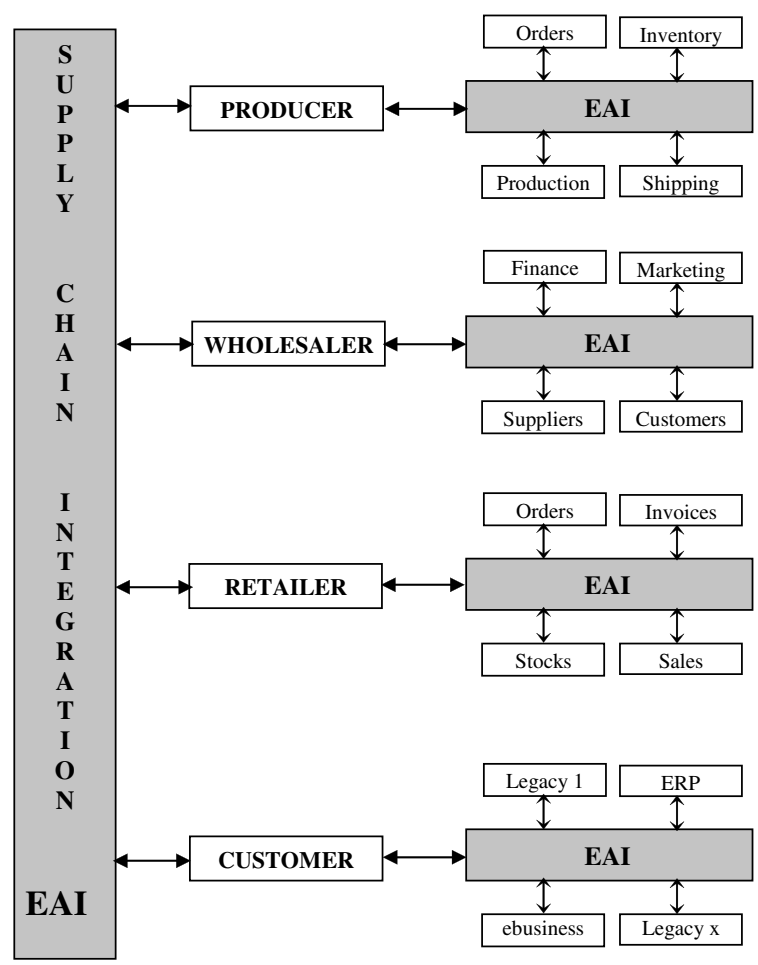

Fig. 1. Supply chain integration through EAI technology.
- EAI can be used to piece together all intraorganisational applications of supply chain partner (e.g. producer). In doing so, a common integrated IT infrastructure is build based on EAI technology. Then, all the applications like orders, production, shipping, inventory, etc. are integrated with EAI infrastructure. Such an infrastructure allows the members of an internal supply chain to exchange data as well as to better coordinate and integrate the tasks of their chain.

- At inter-organisational level, all the members of a supply chain like wholesalers, producers, customers and retailers build a common EAI architecture that unifies all the IS that automate their supply chains. As a result, they connect their internal EAI infrastructures with the external. A critical issue that should be addressed at both levels deals with the control and the ownership of the business processes of a supply chain. This issue is in accordance with supply chain literature as it well discussed by many authors like Bartezzaghi [1], D’Amours et al. [4].

The type (loose, tight) of the integration forms another critical issue that should be addressed by organisations when taking decisions for integrating their supply chains. Based on these two types of integration supply chain partners can form: (a) loose-coupled training partnerships through which share information or (b) tightly integrated chains where there is a higher degree of process dependency. The differences among the types of integration are well discussed in literature with Themistocleous and Irani [27] summarising these in Table 1.

On the tight type, integration is significant factor, with a number of enterprises sharing common data and processes. In this case, enterprises attempt to function as one (virtual) organisation. For instance, a food retailer and its suppliers integrate their IT infrastructures to control and improve promotion management. Suppliers might gain access to retailer IT infrastructure and retrieve information relating to their own products and promotions. Suppliers could analyse the availability and sales of their products, and replace them according to the agreement they have with 
Table 1

Loose and tight type of integration

\begin{tabular}{|c|c|}
\hline Loose integration & Reference \\
\hline Focuses on exchanging-sharing data among partners & Kalakota and Robinson [13] \\
\hline Low degree of processes dependency & Loinsky [18] \\
\hline Low degree of integration & Brown [2] \\
\hline $\begin{array}{l}\text { The development of a homogeneous integrated cross-enterprise infrastructure is not } \\
\text { important }\end{array}$ & Helm [10] \\
\hline Asynchronous communication & Puschmann and Alt [20] \\
\hline Tight integration & Reference \\
\hline Focuses on integrating cross-enterprise business processes and systems & Themistocleous et al. [28] \\
\hline Highest degree of processes dependency & Kalakota and Robinson [13] \\
\hline High degree of integration & Brown [2] \\
\hline $\begin{array}{l}\text { The development of a homogeneous integrated cross-enterprise infrastructure is } \\
\text { important }\end{array}$ & Helm [10] \\
\hline Synchronous communication & Puschmann and Alt [20] \\
\hline
\end{tabular}

Source: Themistocleous and Irani [27].

the retailer. In such a scenario, both suppliers and retailer share common business processes and IT infrastructures.

From a technical perspective, Themistocleous et al. [29] propose that EAI is achieved at three integration layers namely:

- Transportation layer, which transfers the information from source application to the integration infrastructure and from the latter to the target application.

- Transformation layer that translates the information from source application format to target system structure.

- Process automation layer, which integrates the business processes and controls the integration mechanism.

Application elements like data, objects and processes are transferred from the source application to the target through the integration layers. The source and target applications can be systems that are based on packaged (e.g. ERP), custom (e.g. legacy) and e-business (e.g. e-store) categories. The authors have conducted an extensive review of the normative literature and analysed 15 case studies (e.g. General Motors, Bosch Group, Fujitsu Corporation). In doing so, identifying the permutations of system types that are pieced together in inter-organisational supply chains. Table 2 illustrates that organisations integrate the three aforementioned system types (custom, packaged and e-business solutions) by making all (seven) unique permutations. Based on these permutations, the authors define classifications of system types that are integrated a supply chain with Table 2 explains these classifications.

\section{Evaluation framework}

This paper has highlighted that integration is an obstacle for most organisations, yet many technologies claim to overcome integration problems. However, it appears that there is no single integration technology (e.g. ebXML, .net) that support all integration problems. Therefore, permutations of integration technologies can support inter-organisational EAI. However, since there are many technologies available there is a resulting large number of permutations available to support integration efforts. The authors of this paper therefore propose a framework to support the selection of appropriate permutations of integration technologies when organisations seek to integrate one or more classifications of system types. 
Table 2

Classifications of system types that are integrated

\begin{tabular}{|c|c|}
\hline Classifications of system types & Description \\
\hline $\begin{array}{l}\text { Custom-to-custom } \\
\text { integration }\end{array}$ & $\begin{array}{l}\text { Intra-organisational EAI requires the integration of applications on both enterprise and cross- } \\
\text { enterprise level. In incorporating all required systems, many custom applications like legacy } \\
\text { applications and data warehouses are integrated in a common infrastructure, to fully automate } \\
\text { business processes. As custom systems were not developed to collaborate with other systems, they } \\
\text { have limited points of access-integration. In particular, databases and user interfaces are the only } \\
\text { possible points of integration in the majority of custom applications. A typical scenario of this } \\
\text { classification could be the incorporation of legacy systems that deal with promotions management } \\
\text { (e.g. stocks, suppliers accounts). In this case, data from databases and user interfaces should be } \\
\text { extracted and sent from one organisation (e.g. retailer) to another (e.g. supplier). Therefore, } \\
\text { technologies that extract data from a database or a screen are needed to support this classification } \\
\text { of systems }\end{array}$ \\
\hline $\begin{array}{l}\text { Custom-to-packaged } \\
\text { integration }\end{array}$ & $\begin{array}{l}\text { This is a common approach when organisations adopt EAI since packaged applications like ERP } \\
\text { systems have in many cases failed to achieve integration and co-exist alongside custom } \\
\text { applications. A typical scenario of this type could be the integration of a legacy system that deals } \\
\text { with production, and an ERP module that handles customer orders or suppliers' details/accounts. } \\
\text { Although, ERP systems were not designed to incorporate other autonomous applications, a } \\
\text { diversity of approaches techniques and tools can be used to achieve integration between ERP } \\
\text { systems and disparate applications. From a technical perspective, the incorporation of ERP } \\
\text { systems can be achieved on various levels including data, objects/components, and at an interfaces } \\
\text { level }\end{array}$ \\
\hline $\begin{array}{l}\text { Custom-to-e-business } \\
\text { integration }\end{array}$ & $\begin{array}{l}\text { Many e-business solutions require close collaboration with legacy applications to support e- } \\
\text { business enabled processes and tasks. As a result, custom applications (e.g. stocks) are } \\
\text { incorporated with ebusiness systems to integrate and automate inter-organisational business } \\
\text { processes. Likewise, in many cases the functionality of an ebusiness solution is used to support } \\
\text { custom systems. For instance, an e-store updates a custom system that deals with stock } \\
\text { availability. The information provided by the e-business solution is critical not only for the } \\
\text { functionality of stock application but also for the whole supply chain as it supports the automation } \\
\text { and integration of specific business processes. Technologies that support the incorporation and } \\
\text { exchange of data, objects, and interfaces are required to support this classification of systems }\end{array}$ \\
\hline $\begin{array}{l}\text { Packaged-to-packaged } \\
\text { integration }\end{array}$ & $\begin{array}{l}\text { In this case disparate packaged systems such as different versions of an ERP system or different } \\
\text { ERP modules that exist in one organisation are unified into a common integrated infrastructure. } \\
\text { APIs are provided by ERP systems to allow other applications to access ERPs functionality or } \\
\text { data. Data, messages or objects can be inputted or outputted to an ERP system through APIs. } \\
\text { Therefore, the packaged to packaged incorporation requires APIs as well as technologies that } \\
\text { support the extraction and transmission of data, messages and objects }\end{array}$ \\
\hline $\begin{array}{l}\text { Packaged-to-e-business } \\
\text { integration }\end{array}$ & $\begin{array}{l}\text { Organisations take advantage of EAI and electronic commerce technology when they integrate } \\
\text { their e-business solutions with packaged applications as ERP systems can be used as back-office } \\
\text { system to support the e-business functionality (front-end application). In this case, processes that } \\
\text { deal with e-sales, e-procurement and e-supply chain management are integrated with packaged } \\
\text { systems. E-business applications are often based on distributed object technologies (DOT) (e.g. } \\
\text { enterprise Java beans, CORBA, DCOM/COM) and/or internet oriented languages/standards (e.g. } \\
\text { XML, HTML). Thus, technologies that piece together data, objects, interfaces and messages are } \\
\text { significant for the integration of packaged and e-business integration }\end{array}$ \\
\hline $\begin{array}{l}\text { Ebusiness-to-ebusiness } \\
\text { integration }\end{array}$ & $\begin{array}{l}\text { In this approach, an e-business application is integrated and supports the functionality of another } \\
\text { e-business solution. For example an electronic point of sales is incorporated with e-supply chain } \\
\text { management to share data that are important for the latter application (e.g. customer orders, } \\
\text { customer details, etc.). The integration of e-business applications can be facilitated by message } \\
\text { based technologies (e.g. XML), distributed object technologies (e.g. CORBA), and database } \\
\text { oriented technologies (Java database connectivity, JDBC) }\end{array}$ \\
\hline $\begin{array}{l}\text { Custom-to-packaged- } \\
\text { to-e-business } \\
\text { integration }\end{array}$ & $\begin{array}{l}\text { Such approach focuses on the development of an integrated infrastructure that integrates processes } \\
\text { and applications on departmental, enterprise or cross-enterprise level. The types of systems that } \\
\text { are incorporated require integration technologies that support all integration levels. Therefore, } \\
\text { technologies that facilitate the data, object, interface and message level are required }\end{array}$ \\
\hline
\end{tabular}


The proposed framework evaluates integration technologies and thus, highlighting possible permutations of integration technologies available. As explained in Section 3 application elements (data, objects, processes) are extracted from one application and converted through the three integration layers (transportation, translation and process automation) before reaching the target application. In addition, the systems that are integrated follow one or more permutations of system types described in Table 2. This indicates that application elements, integration layers and classifications of system types that are integrated in interorganisational EAI should be adopted as evaluation criteria of the proposed framework. The explanation for this decision is that organisations need to clarify which technologies support the integration of their supply chain systems. In doing so, organisations need to investigate which technologies support the integration of application elements, permutations of system types and integration layers. The proposed evaluation framework is summarised in Table 3.

The ranking of integration technologies follows a low $(\bigcirc)$, medium $(\bullet)$, high $(\bullet)$ scale of ranking similar to the scale used by Miles and Huberman [19]. In addition, two other symbols are used for ranking. The symbol (-) indicates that there is no available information where the symbol $(x)$ codes that an integration technology does not support the integration of a specific classification. Table 4 presents the proposed novel evaluation framework. The assessment of integration technologies in Table 4 is based on evidences derived from an extensive literature review.

Table 3

Proposed evaluation criteria

\begin{tabular}{lll}
\hline \multicolumn{2}{l}{ Evaluation criteria } & \\
\hline $\begin{array}{l}\text { Application } \\
\text { elements }\end{array}$ & $\begin{array}{l}\text { Integration } \\
\text { layers }\end{array}$ & $\begin{array}{l}\text { Classification of system } \\
\text { types }\end{array}$ \\
\hline - Data & - Transporta- & - Custom-to-custom \\
- Objects & tion layer & - Custom-to-packaged \\
- Processes & - Transforma- & - Custom-to-e-business \\
& tion layer & - Packaged-to-packaged \\
& - Process auto- & - Packaged-to-e-business \\
& mation layer & - Custom-to-packaged-e- \\
& & business \\
\hline
\end{tabular}

\section{Case data and analysis}

The authors of this paper conducted a case study to test the proposed evaluation framework. Since, the authors cannot generalise the data derived from a single case study, they suggest that the proposed framework will allow others to relate their experiences to those reported herein. Hence, this paper offers a broader understanding of the phenomenon of EAI evaluation. The empirical data presented here were collected using various data collection methods such as interviews, documentation, and observation. The bias that is considered to be a danger in using a qualitative research approach is overcome in this research through data triangulation. For the purpose of this paper, three types of triangulation are used namely: (a) data [5]; (b) methodological and, (c) interdisciplinary triangulation [11].

The company studied is a large multinational that operates in more than 130 countries and its annual turnover was $€ 33.8$ billions. The authors use the name PRODUCER to refer to this company. PRODUCER is divided into four business units/sectors namely: (a) automotive equipment; (b) communication technology; (c) consumer goods and, (d) capital goods. It has an IT infrastructure that consists of more than 2000 legacy systems, 100 ERP applications and 125 e-business modules. The company run a pilot project to test whether EAI supports a robust IT infrastructure that achieves: (a) closer collaboration with customers and suppliers and, (b) better coordination of business processes and supply chains. The project was focusing on the integration of 12 business processes including supply chain management, customer and supplier relationship management.

At a technical level, EAI was adopted to piece together PRODUCER's customers and suppliers with its business units. For that reason, PRODUCER developed one EAI infrastructure in each business unit and one among business units, customers and suppliers. As illustrated in Fig. 2, the EAI infrastructure integrates the SAP R/3 system with custom-built systems that deal with material management. At an inter-organisational level, it incorporates systems that are based at PRODUCER's suppliers and customers and are used to 
Table 4

Evaluation of integration technologies

\begin{tabular}{|c|c|c|c|c|c|c|c|c|c|c|c|c|c|c|}
\hline \multirow{3}{*}{$\begin{array}{l}\text { Category of } \\
\text { integration } \\
\text { technolo- } \\
\text { gies }\end{array}$} & \multirow{3}{*}{$\begin{array}{l}\text { Integration } \\
\text { technolo- } \\
\text { gies }\end{array}$} & \multicolumn{13}{|c|}{$\underline{\text { Evaluation criteria }}$} \\
\hline & & \multicolumn{3}{|c|}{ Applications elements } & \multicolumn{3}{|c|}{ Integration layers } & \multicolumn{7}{|c|}{ Classifications of system types } \\
\hline & & Data & Objects & Process & $\begin{array}{l}\text { Trans- } \\
\text { portation }\end{array}$ & $\begin{array}{l}\text { Transla- } \\
\text { tion }\end{array}$ & $\begin{array}{l}\text { Process } \\
\text { automa- } \\
\text { tion }\end{array}$ & $\begin{array}{l}\text { Custom- } \\
\text { to-cus- } \\
\text { tom }\end{array}$ & $\begin{array}{l}\text { Custom- } \\
\text { to-pack- } \\
\text { aged }\end{array}$ & $\begin{array}{l}\text { Custom- } \\
\text { to-e-busi- } \\
\text { ness }\end{array}$ & $\begin{array}{l}\text { Pack- } \\
\text { aged-to- } \\
\text { packaged }\end{array}$ & $\begin{array}{l}\text { Pack- } \\
\text { aged-to- } \\
\text { e-busi- } \\
\text { ness }\end{array}$ & $\begin{array}{l}\text { E-busi- } \\
\text { ness-to- } \\
\text { e-busi- } \\
\text { ness }\end{array}$ & $\begin{array}{l}\text { Custom- } \\
\text { to-pack- } \\
\text { aged-to- } \\
\text { e-busi- } \\
\text { ness }\end{array}$ \\
\hline \multirow{2}{*}{$\begin{array}{l}\text { Database } \\
\text { oriented } \\
\text { middleware }\end{array}$} & ODBC & $\bullet$ & $x$ & $x$ & $\times$ & $\nu$ & $x$ & $\ominus$ & $\ominus$ & $\ominus$ & - & 0 & ? & $\bullet$ \\
\hline & JDBC & $\bullet$ & $x$ & $x$ & $x$ & 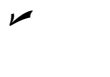 & $x$ & O & $\ominus$ & $\ominus$ & $\ominus$ & $\bullet$ & $\bullet$ & $\ominus$ \\
\hline \multirow{4}{*}{$\begin{array}{l}\text { Message } \\
\text { oriented } \\
\text { technolo- } \\
\text { gies }\end{array}$} & RPC & $\nu$ & $\times$ & $x$ & - & $x$ & $\times$ & 0 & O & O & $x$ & $x$ & $x$ & 0 \\
\hline & MOM & $\nu$ & O & $\times$ & - & $x$ & $x$ & $\ominus$ & $\ominus$ & $\ominus$ & O & O & $\times$ & O \\
\hline & $\begin{array}{l}\text { Message } \\
\text { broker }\end{array}$ & $レ$ & O & $レ$ & • & - & $\bullet$ & - & $\bullet$ & - & - & $\bullet$ & $\bullet$ & - \\
\hline & XML & レ & $\nu$ & $x$ & - & $\bullet$ & $x$ & O & O & $\bullet$ & $\bullet$ & $\bullet$ & $\bullet$ & $\bullet$ \\
\hline \multirow{2}{*}{$\begin{array}{l}\text { Transaction } \\
\text { based tech- } \\
\text { nologies }\end{array}$} & TPM & $\boldsymbol{V}$ & $\times$ & $x$ & $\boldsymbol{r}$ & O & $x$ & $\ominus$ & O & 0 & 0 & O & 0 & O \\
\hline & $\begin{array}{l}\text { Application } \\
\text { serves }\end{array}$ & $\nu$ & $\nu$ & $\times$ & レ & $\times$ & $x$ & $\times$ & $\ominus$ & $\ominus$ & $\ominus$ & $\bullet$ & - & $\ominus$ \\
\hline \multirow{3}{*}{$\begin{array}{l}\text { Distributed } \\
\text { object tech- } \\
\text { nologies }\end{array}$} & CORBA & $\nu$ & • & - & $\nu$ & $\nu$ & - & $\ominus$ & $\ominus$ & $\ominus$ & • & $\bullet$ & $\bullet$ & $\ominus$ \\
\hline & $\begin{array}{l}\text { DCOM/ } \\
\text { COM }\end{array}$ & 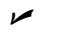 & $\bullet$ & - & $\nu$ & - & - & O & $\ominus$ & $\ominus$ & $\bullet$ & $\bullet$ & $\bullet$ & $\ominus$ \\
\hline & EJB & $\nu$ & $\bullet$ & - & $\nu$ & - & - & O & O & $\ominus$ & $\ominus$ & • & $\ominus$ & \\
\hline \multirow{3}{*}{$\begin{array}{l}\text { Interface } \\
\text { oriented } \\
\text { technolo- } \\
\text { gies }\end{array}$} & $\begin{array}{l}\text { Screen wrap- } \\
\text { per }\end{array}$ & $\nu$ & $v$ & $x$ & $x$ & $v$ & $x$ & $\bullet$ & $\bullet$ & $\bullet$ & O & O & O & - \\
\hline & APIs & $\nu$ & $\nu$ & - & - & $\nu$ & - & - & $\ominus$ & $\times$ & $\bullet$ & $\bullet$ & $\bullet$ & $\bullet$ \\
\hline & Adapters & $\nu$ & V & $\times$ & $\times$ & $\nu$ & $x$ & - & $\ominus$ & $\ominus$ & $\bullet$ & $\bullet$ & $\bullet$ & $\bullet$ \\
\hline
\end{tabular}




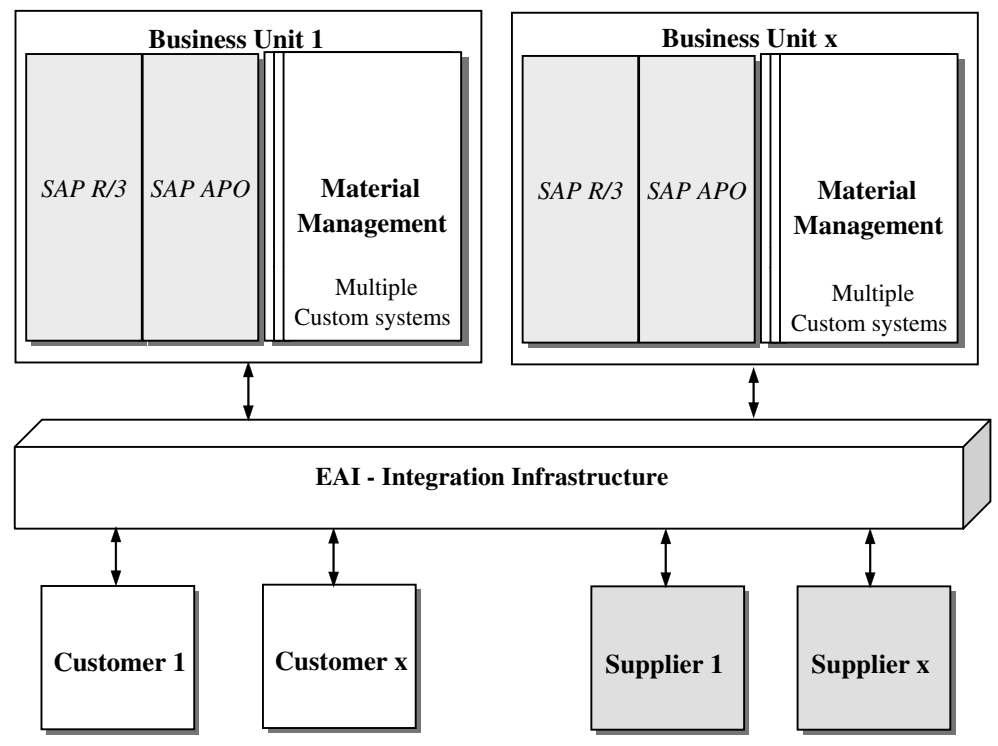

Fig. 2. Pilot project-supply chain integration.

automate common business processes. SAP R/3 and its module that supports advanced planner optimiser (APO) function in an integrated way, since SAP R/3 is an integrated suite. This means that all SAP modules are internally integrated with the core system. Also, APO is unified with material management and other systems (e.g. customers) through the integration infrastructure.

\subsection{Evaluation}

The following subsection contributes towards the assessment of the novel evaluation framework that was proposed in Section 4. In achieving this, those evaluation criteria considered to support the assessment of integration technologies are identified, when seen from a multiple-stakeholder perspective. These views were seen from those stakeholders that were involved in the evaluation and implementation of EAI, as it was not possible to interview all stakeholders. The stakeholders that were interviewed using a structure interviews included: (a) an external consultant (EC); (b) an integrator (Int.) and, (c) the project manager (PM) of the project. In addition, a total of 8 other stakeholders were also interviewed during the case study (unstructured interviews).
Although the organisation has developed its own evaluation framework when assessing integration technologies it was unable to provide any information on its framework due to confidentiality reasons. Nonetheless, there is much confusion regarding integration technologies, and the company has invested in time and knowledge to develop its evaluation framework. Therefore, the case company believes that the framework represents a kind of competitive advantage.

Interviewees were asked to identify the importance of the evaluation criteria and then, to assess the integration technologies using the three categories of evaluation criteria (see Table 3). All interviewees found the proposed framework as one that allows them to clarify many difficulties in selecting integration technologies. Nearly, all of them pointed out the importance of criteria such as the types of systems that are integrated or the integration layers. However, not all interviewees share the same perceptions regarding the integration of custom-to-custom applications. External consultant reported that this is of low significance with project manager and integrator saying that it is of medium and high importance, respectively.

The external consultant reported that custom-tocustom applications incorporation (as a criterion) 
is not important for their organisation, since this type of integration is required in only a few cases. Interviewees mentioned that organisations should not focus on one or another category of evaluation criteria when assessing integration technologies but, take all of them into consideration. More specifically external consultant said that

All sets of criteria are too important for the evaluation of integration technologies. I believe that organisations have to consider all these criteria and assess technologies in a similar way.

In addition, interviewees found the proposed framework very helpful and they reported that it improves IT sophistication and supports decision making for EAI adoption. The reasoning is that the proposed framework supports decisionmaking and allows the IT departments, to better understand the capabilities of integration technologies, as well as their integration requirements. Moreover, they express their intention to adopt the proposed framework.

Then interviewees were asked to evaluate the integration technologies using the three categories of criteria identified in Section 4. The interviewees' evaluation results show that there is no single technology that supports the integration of all applications' elements. This is in accordance with literature findings like Sharma et al. [22] and, indicates that a combination of technologies is required to facilitate the integration of data, objects and processes. When the project manager was asked to comment his answers he said:

Many technologies support the integration of data, objects and processes. Some of these technologies such as message brokers and adapters are more powerful solutions than others... It is difficult to say which is the best using this table [Table 6]. First of all we have to understand the applicability of each technology and that's why we have to map them against integration layers ... Integration layers allow us to see which technologies support a layer. In each layer we have to seek for technologies that support all applications elements.
Thereafter, interviewees were asked to assess integration technologies using the second category of evaluation criteria (integration layers). The interviewees reported that practically message brokers are not used to support transportation layer although they can support it. This is attributed to that developers preferring to use message brokers for the translation and process automation layer and adopt other technologies for transportation layer. In addition to the aforementioned integration layers, interviewees consider connectivity as an integration layer. When an external consultant was asked to explain more this perception, he said:

We consider connectivity as an important integration layer. This layer [connectivity] is responsible for creating the connections-interfaces among the applications and the central integration infrastructure. Through these connections application elements are passed from one system to the transportation layer. Then transfers these elements to the central integration infrastructure where transformation and process automation are taken place.

Then, interviewees were asked to assess the integration technologies based on the third category of evaluation criteria (system types). Based on their answers, it appears that message brokers support the integration of all system types. This is in line with both the literature $[15,17,21,22]$ and practice with EAI vendors using message brokers as the main integration engine of their EAI solutions. Adapters and XML appear to support all or nearly all system types.

\section{Concluding comments}

This paper has highlighted the importance of improving supply chain management through the integration of business processes and information systems. However, there remains no single integration technology that addresses all integration problems. As a result, multiple permutations of technologies need to be used to solve integration problems. Yet, there is a plethora of IS with different integration requirements that need to be 
integrated. This means that the permutation of integration technologies used to unify applications are not only based on their functionality but also on integration requirements, and constrains of existing IS infrastructures. Therefore, organisations are often left questioning how to navigate through the permutations of integration technologies needed to integrate the disparate applications that often exist within businesses and cross-enterprises.

This paper has introduced an approach to reduce the confusion surrounding inter-organisational application integration. In support of this, the types of IS that are often integrated have been classified as

(a) custom-to-custom;

(b) custom-to-packaged;

(c) custom-to-e-business;

(d) packaged-to-packaged;

(e) packaged-to-e-business;

(f) e-business-to-e-business and

(g) custom-to-packaged to e-business inter-organisational EAI.

Through defining the types of IS, much of the confusion surrounding inter-organisational EAI is reduced. The reason for this is that the generic characteristics of each type and its integration requirements are described. As a result, organisations can more easily subsume their systems in one or more of these classifications and start studying in detail their integration requirements. To integrate their applications, organisations need to select a number of integration technologies. In support of this, the authors propose an evaluation framework to assess EAI technologies. The framework correlates the capability of integration technologies to the types of information systems that are pieced together in inter-organisational EAI. The proposed framework confirmed that

- the classification of custom to custom EAI can be integrated more efficiently when message brokers and screen wrappers are used. In those instances that custom applications allow access to databases, ODBC drivers can also facilitate the extraction and inputting of data from custom applications database.

- the classification of custom to e-business applications can be integrated using a permutation of XML, message brokers and screen wrappers can be adopted to achieve integration. Nonetheless, CORBA or COM/DCOM can also accommodate the integration of this classification of system types. CORBA and COM/DCOM can be combined with XML to support objects integration.

- in those instances that custom, packaged and ebusiness solutions are integrated, Application programming interfaces (APIs) can be combined with XML, CORBA, COM/DCOM, message brokers and screen wrappers to piece application together.

To validate the proposed framework, the authors conducted a case study. In doing so, allowing others to relate their experiences to those reported in above. It is not the intention of this section to offer prescriptive guidelines to the evaluation of EAI technologies but rather, describe case study perspectives that allow others to relate their experiences to those reported. A number of conclusions have been extrapolated from the empirical data and include

- The organisation took the decision to evaluate integration technologies before the implementation of EAI projects. The company has developed an evaluation framework for the assessment of integration technologies. It appears that the organisation invested money and time to develop their frameworks, understand and evaluate EAI technologies. Moreover, they believe that such a framework is an important decision-making tool that influenced their decisions to adopt EAI technology.

- Empirical evidence indicates extensions to the framework for the evaluation of integration technologies proposed in Section 4. The organisation suggested additional criteria for the proposed framework included the connectivity layer.

- The proposed framework can be used as a decision-making tool and supports the adoption of 
integration technologies. In support of this, the case company expressed its intention to adopt the proposed framework, which indicates the importance of such a framework.

The novelty of the proposed framework contributes towards a better understanding of the capabilities of each technology, and allows decision-makers to clarify the confusion surrounding integration technologies. Such a framework can be used as a frame of references to highlight possible combinations of integration solutions that can address the integration of information systems. Also, the proposed framework improves IT sophistication since it contributes to understanding the capabilities of integration technologies.

\section{Acknowledgements}

The authors are most grateful to anonymous referees that have made numerous contributions to the development of this paper. Also, the Guest Editor, Prof. Gunasekaran for his helpful and constructive comments, which improved this manuscript. Finally, the authors would like to acknowledge the Engineering and Physical Sciences Research Council (EPSRC) Grant (GR/ R08025).

\section{References}

[1] E. Bartezzaghi, The evolution of production models: Is a new paradigm emerging, International Journal of Operations and Production Management 19 (2) (1999) 229-250.

[2] L. Brown, Integration Models: Templates for Business Transformation, SAMS Publishing, USA, 2000.

[3] M.G. Christopher, Logistics and supply chain management, Pitman Publishing, London, 1992.

[4] S. D'Amours, B. Montreuil, P. Lefrancois, F. Soumis, Networked manufacturing: The impact of information sharing, International Journal of Production Economics 58 (1999) 63-79.

[5] N.Y.K. Denzin, The Research Act: A Theoretical Introduction to Sociological Methods, McGraw-Hill, New York, 1978.

[6] S. Duke, P. Makey, N. Kiras, Application Integration Management Guide: Strategies and Technologies, Butler Group Ltd, Hull, 1999.
[7] J. Gattorna, Strategic Supply Chain Alignment: Best Practice in Supply Chain Management, Ashgate Publishing Co, Aldershot, Hampshire, 1998.

[8] J. Gjerdrum, N. Shah, L. Papageorgiou, Production, manufacturing and logistics fair transfer price and inventory holding policies in two-enterprise supply chains, European Journal of Operational Research 143 (2002) $582-599$.

[9] G. Gunnarsson, S. Jonsson, Charge the relationships and gain loyalty effects: Turning the supply link alert to IT opportunities, European Journal of Operational Research 144 (2003) 257-269.

[10] R. Helm, Extending EAI beyond the enterprise, EAI Journal (1999).

[11] V. Janesick, The choreography of qualitative research design, in: Y.S. Lincoln (Ed.), Handbook of Qualitative Research, Sage Publications, Thousand Oaks, CA, 2000, pp. 379-399.

[12] R. Kalakota, Inter-enterprise fusion - the future of supply chains, EAI Journal (2000) 72-76.

[13] R. Kalakota, M. Robinson, e-Business: Roadmap for Success, Addison-Wesley, Boston, MA, 1999.

[14] D.M. Lambert, M.C. Cooper, Issues in supply chain management, Industrial Marketing Management 29 (2000) 65-83.

[15] D. Linthicum, B2B Application Integration, First ed., Addison-Wesley, Reading, MA, 2000.

[16] D. Linthicum, Enterprise Application Integration, First ed., Addison-Wesley, Reading, MA, 1999.

[17] D. Linthicum, Mercator: Next Generation Application Integration, Mercator Software, Wilton, CT, 2001, 15 pp.

[18] S. Loinsky, Enterprise-Wide Software Solutions: Integration Strategies and Practices, Addison-Wesley-Longman Inc, USA, 1995.

[19] M.B. Miles, A.M. Huberman, Qualitative Data Analysis: An Expanded Sourcebook, Sage Publications, Newbury Park, CA, 1994.

[20] T. Puschmann, R. Alt, Enterprise application integration-The case of the Robert Bosch Group, in: CD Proceedings of the 34th Hawaii International Conference on System Sciences, Maui, HI, 2001.

[21] K. Ring, N. Ward-Dutton, Enterprise Application Integration: Making the Right Connections, First Ed., Ovum Ltd, London, 1999.

[22] R. Sharma, B. Stearns, T. Ng, J2EE Connector Architecture and Enterprise Application Integration, AddisonWesley, Reading, MA, 2001.

[23] R.E. Spekman, K. JW, N. Myhr, An empirical investigation into supply chain management: A perspective on partnership, Supply Chain Management 3 (2) (1998) 53-67.

[24] G. Stefansson, Business-to-business data sharing: A source for integration of supply chains, International Journal of Production Economics 75 (2002) 135-146.

[25] M. Themistocleous, Evaluating the Adoption of Enterprise Application Integration in Multinational Organisations, in: Department of Information Systems and Computing, Brunel University, London, 2002. 
[26] M. Themistocleous, Z. Irani, Benchmarking the benefits and barriers of application integration, Benchmarking: An International Journal 8 (4) (2001) 317-331.

[27] M. Themistocleous, Z. Irani, Novel taxonomy for application integration, Benchmarking: An International Journal 9 (2) (2002) 154-165.

[28] M. Themistocleous, Z. Irani, R. O'Keefe, ERP and application integration: Exploratory survey, Business Process Management Journal 7 (3) (2001) 195-204.
[29] M. Themistocleous, Z. Irani, A. Sharif, Evaluating application integration, in: Seventh European Conference on Evaluation of Information Technology (ECITE 2000), 2000, Dublin, Ireland, MCIL Reading, UK, pp. 193202.

[30] U.W. Thonemann, Production, manufacturing and logistics improving supply-chain performance by sharing advance demand information, European Journal of Operational Research 142 (2002) 81-107. 